\title{
CINE GUARANI E O CINEMA EM SANTO ANASTÁCIO
}

Fabrícia Dias da Cunha de Moraes Fernandes Borges, Karen Staquecini Martines.

Universidade do Oeste Paulista - UNOESTE, Faculdade de Engenharias e Arquitetura e Urbanismo, Presidente Prudente, SP. E-mail: karenstaquecini@gmail.com

\section{RESUMO}

Há muito surgiu a arte cinematográfica, principalmente os cinemas de rua; As exibições ganharam o mundo tudo com o passar dos anos, porém, com a interferência de diversos fatores, são poucos os cines de rua que ainda se mantem de portas abertas ao público. Essa decadência dos cinemas de rua resultou em uma enorme perda cultural para a população. Desta forma o objetivo deste estudo foi recuperar memórias e recordações do antigo Cine Guarani em Santo Anastácio, relembrando e reforçando sua identidade. A metodologia constou de escassas informações documentadas, e muitas fotos e informações de jornais, contando com a colaboração da população. Concluímos que o Cine Guarani foi o autor de grandes histórias, e que a sua deveria também ser sempre lembrada.

Palavras-chave: Cinema de rua, Cine Guarani, Decadência, Memória, Patrimônio.

\section{CINE GUARANI AND THE CINEM IN SANTO ANASTÁCIO}

\begin{abstract}
Long did the film art, especially street cinemas; Exhibits won the world all over the years, however, with the interference of various factors, few street cinemas that still keeps its doors open to the public. This decay of street cinemas resulted in a huge cultural loss for the population. Thus the aim of this study was to recover memories and memories of the old Cine Guarani in Santo Anastacio, recalling and reinforcing its identity. The methodology consisted of scarce documented information, and lots of pictures and newspaper information, with the collaboration of the population. We conclude that the Guarani Cine was the author of great stories, and that their should also always be remembered.
\end{abstract}

Keywords: Street Cinema, Cine Guarani, decay, Memory, Patrimony. 


\section{INTRODUÇÃO}

Os cinemas de rua surgiram no ano de 1895 através dos irmãos Lumière, na França. Com o entusiasmo da nova criação, adquiriram um prédio para a difusão cinematográfica e desde então, a sétima arte encanta, choca e desperta fantasias em expectadores de todas as idades. Sua magia despertou interesse em todo o mundo, e os anos de 1930 e 1940, foi de grande difusão para o cinema.

As exibições eram esperadas por todos, e uniam as multidões antes, durante e depois das seções. Segundo Padron (2012) assistir a um filme trazia diversão por completo: as pessoas se arrumavam e compareciam independente do itinerário. A arquitetura dos prédios dos cinemas se destacava, em sua maioria, pelo estilo art déco, e possuíam salas grandiosas com capacidades para mais de mil espectadores.

Com o passar dos anos, diversos fatores contribuíram para a decadência dos cinemas de rua: a desvalorização cultural, a especulação imobiliária, o surgimento dos vídeos cassetes e a chegada dos shoppings centers foram os principais determinantes. Os edifícios dos cines passaram a ter outras funções e grande parte deles foi demolida para a construção de novos locais. Tudo isso resultou em uma perda patrimonial muito grande.

O objetivo deste estudo foi devido construção histórica do patrimônio brasileiro marcada por lacunas derivada da falta de documentos escritos ou mesmo imagens de bens patrimoniais que sofreram uma reestruturação ou foram transformados para a utilização do espaço para outra funcionalidade.

Esta realidade pode constatada em Santo Anastácio, uma vez que as informações sobre o patrimônio histórico municipal perdeu-se pela ausência de documentos que se preocupassem em retratar a história e a importância destes espaços para a população desta localidade e das cidades vizinhas.

\section{METODOLOGIA}

A partir desta premissa compreende-se que a falta de informações sobre a historicidade das cidades pequenas deve-se a inexistência de documentos, sendo necessário utilizar fotos, informações contidas em jornais, documentos públicos, informações provenientes de moradores antigos, que colaborem na reconstrução e preservação da memória cultural. Por fim foi redigido um breve relato sobre o cinema em Santo Anastácio, em especial o Cine Guarani, memória e identidade, sendo analisados e com acompanhamento com orientador.

\section{DISCUSSÃO}

A cidade de Santo Anastácio esta localizada a oeste do estado de São Paulo, e possui uma área de unidade territorial de $552,876 \mathrm{Km}^{2}$ segundo dados do IBGE (2015). Desenvolveu-se a partir da estrada de ferro alta sorocabana, possui atualmente 21.044 habitantes (IBGE, 2015,). Sua infraestrutura antes baseada no algodão e na agropecuária aponta hoje para o comercio.

Conforme Ávila Junior (1995, p. 233) o primeiro cinema de Santo Anastácio foi construído na década de 1920, época áurea do surgimento dos cinemas, pertencendo ao Sr. Henrique Nicolino Rinaldi. O Cine Theatro Santa Catarina era feito de madeira (Figura 01) e funcionava aos domingos. Este espaço também era utilizado para realização de eventos sociais como bailes, encenação de peças teatrais ampliando as possibilidades de utilização deste espaço. 


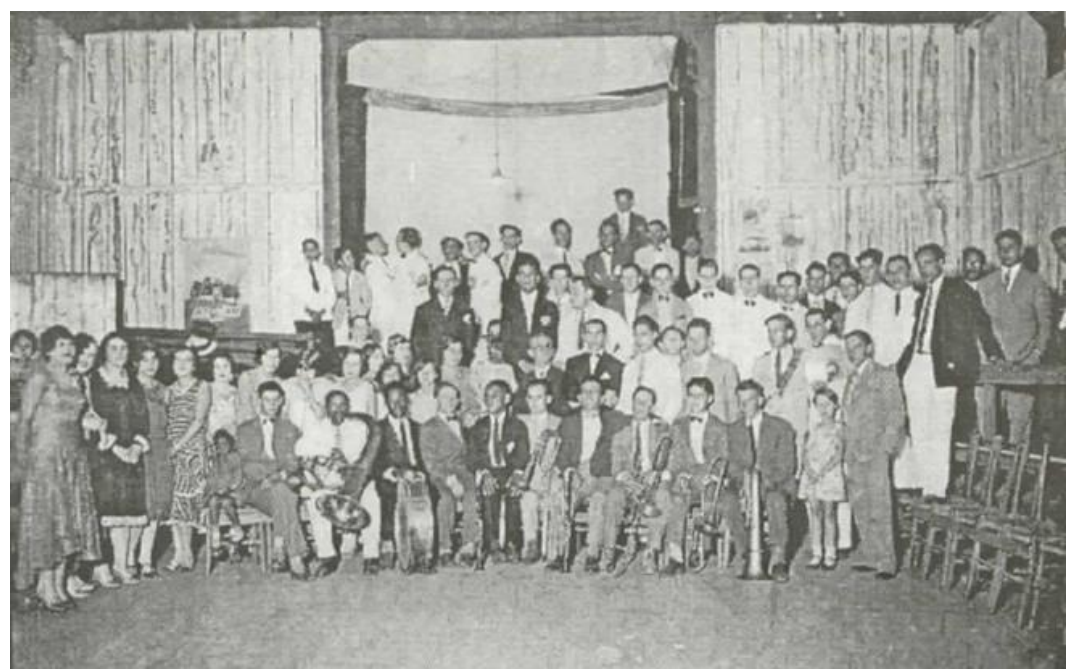

Figura 01. Cine Theatro Santa Catharina no Barracão de Madeira de propriedade de Henrique Nicolino Rinaldi no ano de 1930

Fonte: Celso Jaloto Ávila Junior, 1995.

Verifica-se que os cinemas de rua contribuíam para a realização de diversos eventos culturais, de forma que a comunidade contava com uma referência, um espaço cultural no qual as ações produzidas pela mesma pudessem ser compartilhadas.

Em 1930 o Cine Theatro Santa Catharina foi transferido para outro espaço, o qual era um grande salão de alvenaria que acomodava cerca de 1.500 pessoas (Figura 02). "Todas as festas, bailes importantes e cerimônias, passaram a ser feitas em seus salões" (ÁVILA JUNIOR, 1995, p. 234). Seu espaço físico em 1932 foi utilizado para a realização de atividades de patinação, envolvendo disputas com bola ou apresentações, as quais envolviam os jovens do município e das cidades vizinhas.

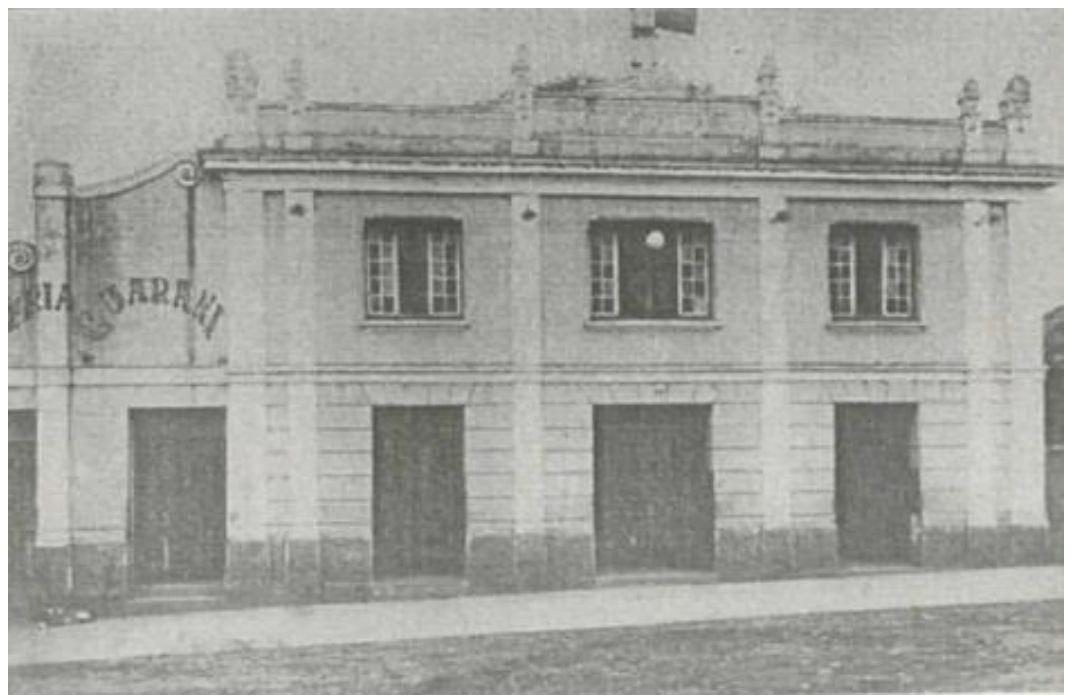

Figura 02. Edifício em Alvenaria do Cine Theatro Santa Catharina Fonte: Celso Jaloto Ávila Junior, 1995.

O interior do Cine Theatro possuía o piso plano e um amplo salão, com cadeiras em madeira, que poderiam ser deslocadas de lugar. Havia também nas laterais do salão as frisas, também com cadeiras móveis. Um palco coberto por uma grande cortina. Seus detalhes arquitetônicos internos, com curvas nos remetem ao estilo art déco, como podemos observar na Figura 03: 


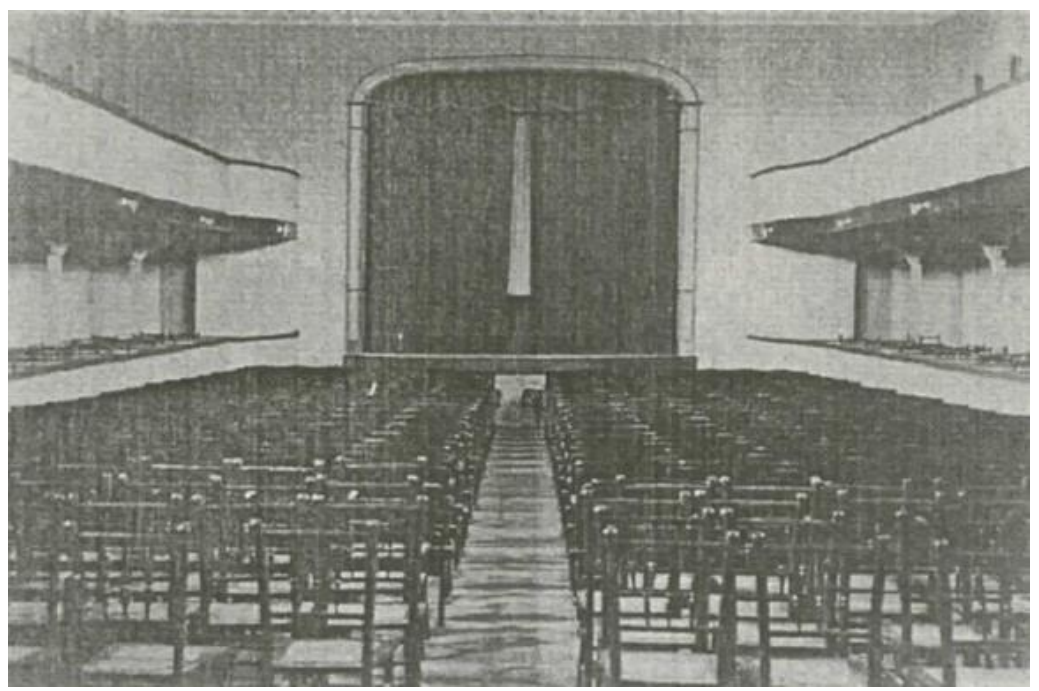

Figura 03. Vista Interna do Cine Teatro Santa Catharina Fonte: Celso Jaloto Ávila Junior, 1995.

No ano de 1933 foi adquirido o aparelho "vita-fone" para a projeção de filmes sonoros, sendo mudado o nome para "Cine Para Todos" e posteriormente para "Cine Popular", por volta do mesmo ano. Mais tarde em 1935 surgiu um conjunto musical conhecido como "Bando da Lua" realizando apresentações de jazz, tendo como principal artista e articulador o Sr. Eduardo Araújo, conhecido como Chocolate (ÁVILA JUNIOR, 1995, p. 238).

Em 1940 a empresa Irmãos Gonçalves arrendou o imóvel, realizando uma nova reforma e mudando o nome para Cine Guarani (Figura 04). Em janeiro de 1948 o cinema foi comprado pelos senhores Jamil Miguel, Jorge Cury e Massat Peres mudando o nome do cinema por um curto espaço de tempo para Cine São Jorge. Logo em seguida retornando o nome para Cine Guarani, e próximo de ser fechado no ano de 1987 possuía o nome de Cine Arte. (ÁVILA JUNIOR, 1995, p. 234).

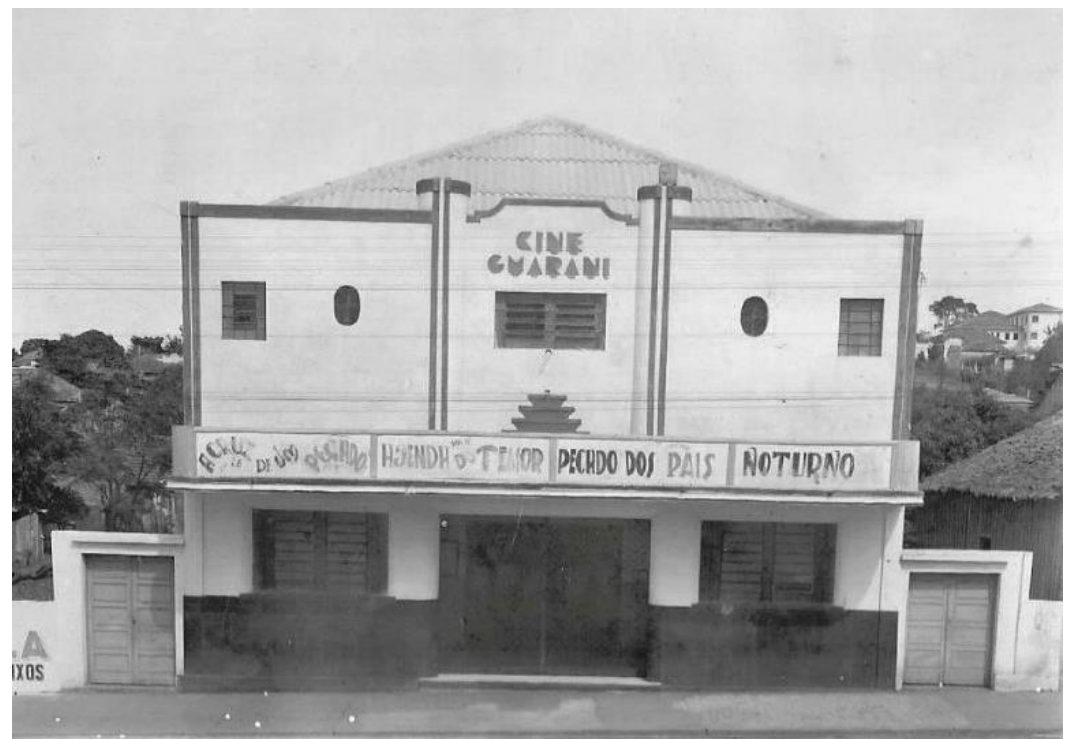

Figura 04. Nova fachada do cinema: O Cine Guarani - 1940

Fonte: Celso Jaloto Ávila Junior, 1995.

A diversidade do espaço físico do Cine Guarani contribuía para a integração da comunidade as ações promovidas pela cultura. Este fator colaborava para o fortalecimento da identidade cultural da população a qual atribuía valor não apenas ao evento, mas também a possibilidade de estabelecer o convívio social. 
Foi no ano de 1984 e 1985 que surgiu o grupo "Etc Y Tal", um grupo de dublagem formado por jovens anastacianos. A banda participou de diversas atividades culturais, e também se apresentou em campeonatos na cidade e na região. Em abril de 1985 ganhou o primeiro lugar no Festival de Dublagem promovido pela Rádio Cultura (Figura 05), interpretando a "Blits", e sendo aplaudido por milhares de pessoas que lotaram o cine Guarani.

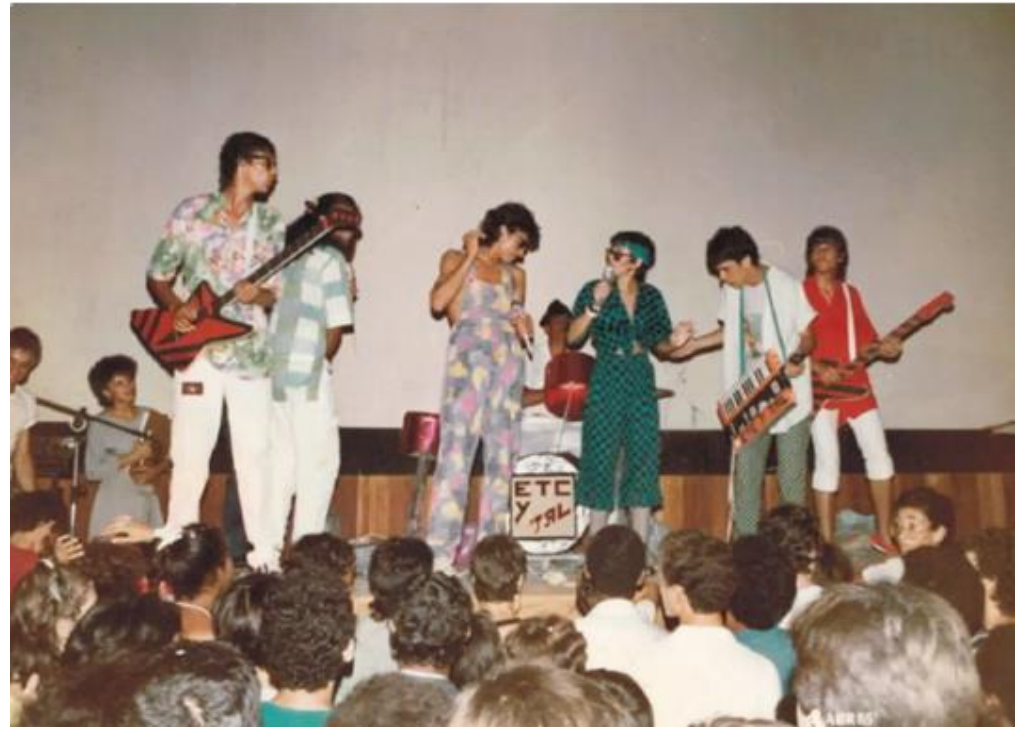

Figura 05.1 Grupo "Etc y Tal" vencedor do Festival de Dublagens Fonte: Solange Mioto, uma das vocalistas do grupo, 1985.

O Cine Guarani foi palco de muitas atrações culturais para a população. Seu interior e sua arquitetura art déco encantavam a todos. É possível perceber todo carinho e admiração pelo espaço no texto de José Carlos Ramires (2009), onde descreve desde a entrada da bilheteria, até o início da sessão:

Ao se entrar na ante-sala, à esquerda o balcão das guloseimas, doces, chocolates, balas. Quem tinha sede tomava água no bebedouro que lá existia, pois de tanta ansiedade as bocas secavam e o sorvido de um gole d'água aplacava a nossa sede, de água e de ansiedade, pois já estávamos na ante-sala, já estávamos dentro. Sem falar que lá também havia sofás, e dos bons, para que, aos que mais cedo chegavam, se permitissem sentar e esperar, das cortinas a sua abertura. (RAMIRES, 2009)

De sua arquitetura interior pouco se tem relatos e fotografias, porém, em pesquisa na comunidade e com os integrantes do grupo vencedor do festival de dublagens, podemos perceber alguns detalhes em fotos. Na Figura 06 podemos observar a grandiosidade da sala do cinema. Suas paredes em pintura branca, com infiltrações do tempo e a marca d'água com detalhes em madeira. Ao fundo notamos ainda um mezanino, que de acordo com a conversa informal, era disputado pela maioria das pessoas. 


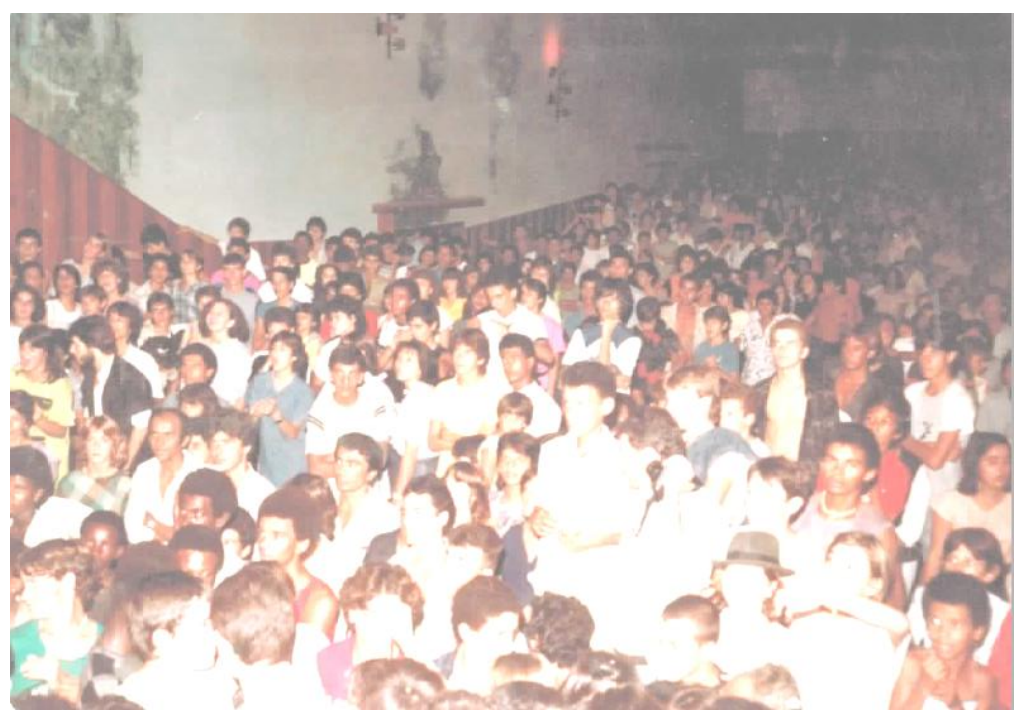

Figura 06. Detalhes Internos do Cine Guarani

Fonte: Solange Mioto, uma das vocalistas do grupo, 1985.

Chegando a hora da sessão o início, um som lindo se ouvia, um som característico, de violinos a entoar uma música, que de tão bela, nos deleitava e nos acalmava. As luzes apagando-se lentamente. As cortinas abrindo-se, uma para cada lado. Um show, um show não, um espetáculo! As cortinas se abrindo, a música se ouvindo e de repente, silêncio... Então, um clarão ilumina a tela branca e um estrondo de som inicia a sessão. (RAMIRES, 2009)

Observamos ainda, na Figura 07, o que Ramires (2009) descreve: as luminárias na parede, que se apagavam lentamente até o início da sessão do cinema. De acordo com relatos informais, os horários eram sempre muito disputados, e em dias de estreias, eram abertos várias seções para atender a quantidade de público.

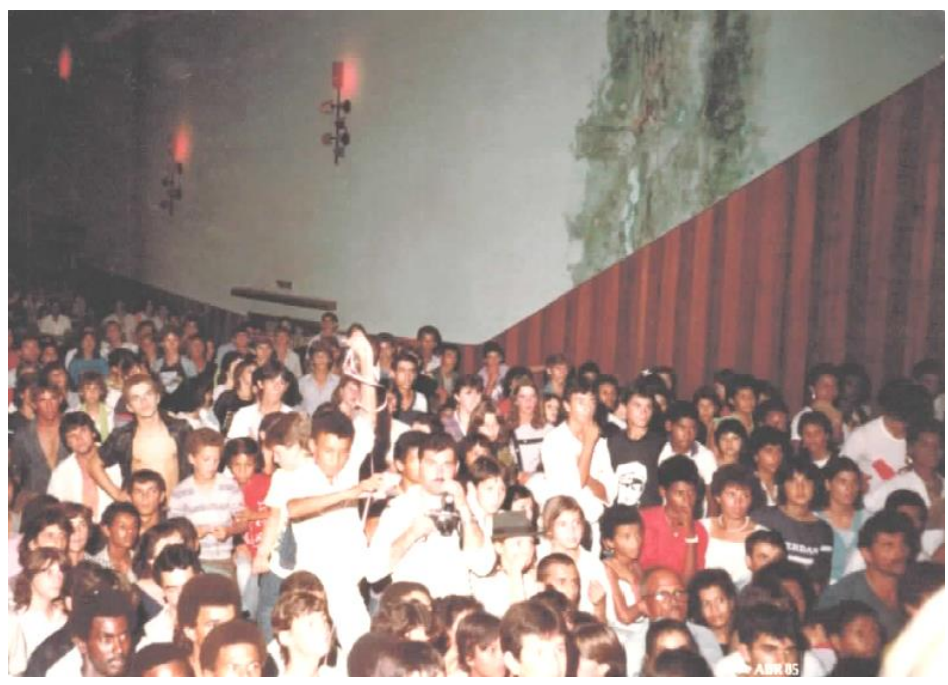

Figura 07. Luminárias no Interior do Cinema

Fonte: Solange Mioto, uma das vocalistas do grupo, 1985.

Uma pessoa de grande destaque para o Cine Guarani em Santo Anastácio, é o Senhor Archimedes Lombardi. Archimedes foi um morador da cidade que, aos seus doze anos de idade, foi convidado a trabalhar na limpeza e organização da sala de exibição do cinema, não recebendo salário em troca, mas podendo levar a família e assistir as sessões de filmes gratuitamente. 
Com doze anos fui trabalhar no cinema. O gerente - seu Nicolau - me contratou para eu varrer o cinema de manhã cedo, limpar as poltronas e deixar tudo prontinho para a sessão da noite. Quando me convidou ele disse "_ Eu não posso te pagar um salário, mas você entra na hora que quiser, assiste o que quiser, traz sua família". Eu fui gostando daquilo. Eu tinha uma carriola e todo dia ia à estação de ferro, receber os filmes. Nós recebíamos tudo em cima dos trilhos. [...] Assim, todos os dias eu buscava os latões dos filmes para o cinema, levava o anterior e pegava o novo na estação do trem. (SESC SP, 2014, p. 2)

Ele quem estava responsável em buscar os latões de filmes para as sessões na estação ferroviária todos os dias, levava os velhos e trazia os novos. Também fazia a guarda dos portões para evitar que as crianças e demais entrassem sem pagar a entrada. Segundo Archimedes (2014) muitos dos garotos que pulavam o muro para entrar eram seus colegas de escola, e certo dia deixou que todos entrassem escondido no final do filme.

Seu Nicolau dizia "_Você fica no corredor prestando atenção, porque tem criança que pula o muro". Uma vez, aconteceu um caso que nunca esqueci. Seu Nicolau fazia pressão para eu não deixar entrar ninguém, mas, muitas vezes, você olhava para o lado do muro e tinha um colega seu de escola. Um dia, eu fiz o quê? Faltavam uns vinte minutos para terminar o filme eu abri o portão e falei “_Entra todo mundo!" ((risos)), me pegaram e me mandaram embora e aí foi uma tristeza. (SESC SP, 2014, p. 2)

Depois de sessenta anos trazendo cultura, entretenimento e diversão para a cidade, o Cine Guarani fechou suas portas. Ninguém sabe ao certo os reais motivos que levaram o cinema a interromper suas atividades, porém acredita-se que foram as mesmas causas dos demais cinemas de rua em todo o mundo.

É difícil admitir, é difícil acreditar, é triste... mas este Guarani a que me refiro está morto. Morto, sem ser velado. Morto sem ser homenageado. Morto, sem choro e nem vela. Só uma fita amarela, representada por uma parede de tábuas retiradas de seu próprio ventre, a isolar e também proteger, os descuidados que em frente passam. (RAMIRES, 2009)

\section{CONCLUSÃO}

O Cine Guarani tinha grande importância na vida de todos na cidade, e hoje existe apenas as recordações. Um edifício que poderia ter se eternizado na cidade hoje vive apenas na lembrança de quem pode vivenciar a experiência de assistir aos espetáculos. Que este artigo seja um principio do resguardo de sua memória e identidade, para que todos conheçam o nosso amado Cine Guarani.

\section{REFERÊNCIAS}

ABNT. Normas e Padrões para Trabalhos Acadêmicos e Científicos da Unoeste.

AVILA JUNIOR, Celso Jaloto. Santo Anastácio: História de uma Cidade. Porto Alegre, Rio Grande do Sul, 1995.

FONSECA, Darci. Cine Saudade - Archimedes Lombardi e seu Domingo de "Iscaramuchi". Julho de 2009. Disponível em: <http://westerncinemania.blogspot.com.br/2014/07/cine-saudadearchimedes-lombardi-e-seu.html> Acesso em 17 de maio de 2016. 
PADRON, Larissa. A quase extinção dos cinemas de rua no país e seus impactos culturais. Disponível em: <http://www.cinemaemcena.com.br/plus/modulos/noticias/ler.php?cdnoticia=43211>. Acesso em 25 de fevereiro de 2016.

RAMIRES, José Carlos. A morte anunciada de um Guarani. Rede Unividas. Fevereiro de 2009. Disponível em: <http://funerariaramires.blogspot.com.br/2009/02/in-memoriam-cineguarani.html> Acesso em 17 de maio de 2016. 